\title{
Management of summer grainage of eri silkworm Samia ricini (Donovan) for better performance
}

\author{
Sarkar B. N. ${ }^{\star}$, Sarmah M. C. and Goswami D. \\ Central Muga Eri Research and Training Institute, Central Silk Board, Lahdoigarh-785700, Jorhat, Assam, India.
}

Accepted 22 March, 2018

\begin{abstract}
Eri silkworm, Samia ricini (Donovan) is multivoltine and has several broods in a year. In the traditional eri growing area of North East India, the farmers conduct eri rearing in four crop seasons, that is, spring, summer, autumn and winter due to spent time in others agricultural crop. Although the suitable climatic conditions are spring and autumn seasons in this zone for eri cocoon production, but during summer the temperature raises up to 35 to $39^{\circ} \mathrm{C}$ with fluctuation of temperature and humidity that interfere in the eri seed production and rearing activities resulted emergence of crippled moths, poor coupling aptitude and poor egg laying capacity, unfertilized eggs, poor embryonic development, desiccation of eggs and leads to hatching failure. In these circumstances, an experiment was conducted to maintain the temperature and humidity in the ITK mode of operation during summer grainage for enhancement of the realized fecundity and hatching percentage and to overcome the others problems during summer grainage. Experimental data revealed that overall performance of grainage characters during summer in the treated lot were significantly better than the control lot.
\end{abstract}

Keywords: Eri silkworm, Samia ricini (Donovan), management, summer grainage, performance.

*Corresponding author. E-mail: bnsarkarcsb@yahoo.com.

\section{INTRODUCTION}

Eri silkworm, Samia ricini (Donovan) is a non-mulberry silkworm and one of the major components of wild (Vanya) silks of India (Singh et al., 2003). The eri silkworm S. ricini (Donovan) belonging to the family Saturnnidae is domesticated and reared indoors like mulberry silkworm, Bombyx mori. The Brahmaputra valley of Assam, India and its adjoining foot hills are believed to be the original home of cultivated eri silkworm. Besides Assam, it is cultivated in Meghalaya, Nagaland, Manipur, Mizoram and Arunachal Pradesh. Further, it is spreading to different non-traditional states like, Andhra Pradesh, Tamil Nadu, Karnataka, Gujarat, Jharkhand, Chhattisgarh etc.

Cultivated eri silkworm is multivoltine in nature and 5 to 6 broods are reared throughout the year (Sarkar, 1980). However, autumn and spring seasons are more suitable for eri silkworm rearing. The larvae of eri silkworm are polyphagous in nature feeding on a number of food plants. Among the different food plants castor, Ricinus communis Linn. is the best suited eri food plants (Hazarika et al., 2010). Based on leaf yield, 10 promising accessions were selected (Gogoi et al. 2006), out of which, NBR-1(non-bloomy red) castor was found as promising variety for eri silkworm rearing with potential leaf yield of $12 \mathrm{MT} /$ ha/year (Sarmah, 2002). Sarkar et al. (2015) confirmed that NBR-2 variety of castor of Ricinus communis $\mathrm{L}$. also found to be the best suited to the larvae of eri silkworm and provides all possible nutrition to the worms for better growth and development among other accessions.

Silkworm egg is considered as the key factor of sericulture industry. Only quality eggs ensure a good harvest and healthy crop. The quality of the seed cocoon is greatly influenced by a number of factors such as 
nutritious leaf, disease free layings, optimum temperature, humidity and hygienic condition. On the other hand, the embryonic development stage in silkworm is very susceptible to environmental conditions, that is, temperature, and humidity etc. and also greatly influenced by quality seed cocoons (Choudhury, 2005). Studies on silkworm nutrition have established that it is the quality of food plants that ultimately reflects on growth and development of silkworm and overall silk production (Sinha et al., 1986). Further, the amount, rate and quality of food consumed by a larva influences the different parameters like growth rate, developmental time, larval weight, survival and reproductive potential (Slansky and Scriber, 1984). Sarkar et al. (2010) reported that high temperature and fluctuation of humidity in summer affect the grainage characters of eri silkworm. The grainage (silkworm seed production centre) activities conducted in the summer season in respect of maximum and minimum temperature and relative humidity were recorded during different grainage periods and an average temperature of $15^{\circ} \mathrm{C}$ and relative humidity of 70 to $80 \%$ which was near optimum range for grainage operation (Samson and Barah, 1989). According to Engelmann (1984), relative humidity ranged from 72 to $78 \%$, which was congenial for development of different stages of eri silkworm during grainage.

Therefore an attempt was made to make an ITK mode of study to observe the seed production during summer in the control temperature and normal room temperature to evaluate performance of moth emergence pattern, ovipositional potency and behaviour, egg characters and egg hatchability percentage in two different conditions.

\section{MATERIALS AND METHODS}

Grainage operation of eri silkworm was conducted in summer season (July to August) at GCC, Chenijan farm of Central Muga Eri Research and Training Institute, Lahdoigarh, Jorhat, Assam, India. Seed cocoons were preserved in the moth emergence cage for easy emergence and crawling to wall of moth cage for pairing. Three grainages from 2015 to 2017 were conducted during high temperature in unfavorable summer climate. For cooling the grainage room and control of the temperature and humidity following methods were adopted.

1) Ventilation of room: During the period of grainage activities door and windows are kept open for free flow of heat wave. To check the insect pest and predator, the door and windows are fitted with insect proof net during grainage activities.

2) Use of wet Gunny cloth: Gunny cloths were fully dipped water in a plastic container and the wet gunny cloths were surrounded the lower portion of the moth emergence cage.

3) Rising of humidity: Filled the concrete floor of grainage room with running water to facilitate Gunny cloths to be wet for controlling the temperature and rising humidity.

4) Discharge of hot air: To maintain room temperature with aeration in the grainage room the exhausted/ceiling fans were used.
During the period of grainage operation the meteorological data of the control and treated rooms were also recorded.

\section{Temperature and relative humidity of grainage period}

The grainage experiment was conducted with preservation of 100 nos. of seed cocoon with equal number of male and female cocoons in one control and treated lot (Table 1). The data on different parameters such as moth emergence pattern, percentage of healthy and invalid moth emergence, potential fecundity, realized fecundity; fertilized eggs, unfertilized eggs and hatching percentage in each treatment and controlled lots were recorded. Emerged male and female moths were paired in the moth cage (Figure 1). After completion of $6 \mathrm{~h}$ pairing, gravid female moths were tied in "Kharika" for egg laying and fecundity with hatching percentage were recorded to study the suitability of different lots. (Figure 2).

\section{RESULTS AND DISCUSSION}

Grainage operation in summer and different characters of seed production was recorded for the control and treatment lot which was presented in Table 2.

\section{Emergence of moth}

\section{Healthy moth}

Emergence of male and female moths were found higher in treated lot than control lot where $88 \%$ moth emergence was recorded in treated lot and it is only $75 \%$ in control lot. The percentage of healthy male moth emergence was $46 \%$ in treated lot and $38 \%$ was recorded in control lot (Table 2). The percentage of healthy female moth emergence was $42 \%$ in treated lot and $37 \%$ was found in control lot. Cocoons remain more unmerged in control lot. The emergence of healthy moth was found maximum in treated lot than normal one in summer climatic condition.

\section{Invalid moth}

The overall percentage of invalid male and female moth emergence was found $6 \%$ in treated lot and $17 \%$ in control lot. The high temperature and humidity in control lot influences normal metamorphosis of eri pupa resulted invalid moth emergence.

\section{Un-emerged cocoon}

The percentage of un-emerged cocoons varies with the treated and control lot. The total un-emerged cocoon was found in case of treated lot is $6 \%$, followed by $8 \%$ in control lot. Therefore it was noted that in treated conditions the required temperature and humidity by artificial method, the moth emergence increased significantly. 
Table 1. Temperature and relative humidity during the experiment period.

\begin{tabular}{|c|c|c|c|c|c|c|c|c|}
\hline \multicolumn{4}{|c|}{ Treated } & \multicolumn{4}{|c|}{ Control } & Remarks \\
\hline \multicolumn{2}{|c|}{ Temperature $\left({ }^{\circ} \mathrm{C}\right)$} & \multicolumn{2}{|c|}{ Humidity (\%) } & \multicolumn{2}{|c|}{ Temperature $\left({ }^{\circ} \mathrm{C}\right)$} & \multicolumn{2}{|c|}{ Humidity (\%) } & \multirow{3}{*}{$\begin{array}{l}\text { Avr. materiological data recorded } \\
\text { for three grainage }\end{array}$} \\
\hline Max. & Min. & Max. & Min. & Max. & Min. & Max. & Min. & \\
\hline 32 & 22 & 72 & 65 & 39.6 & 27 & 70 & 51 & \\
\hline
\end{tabular}
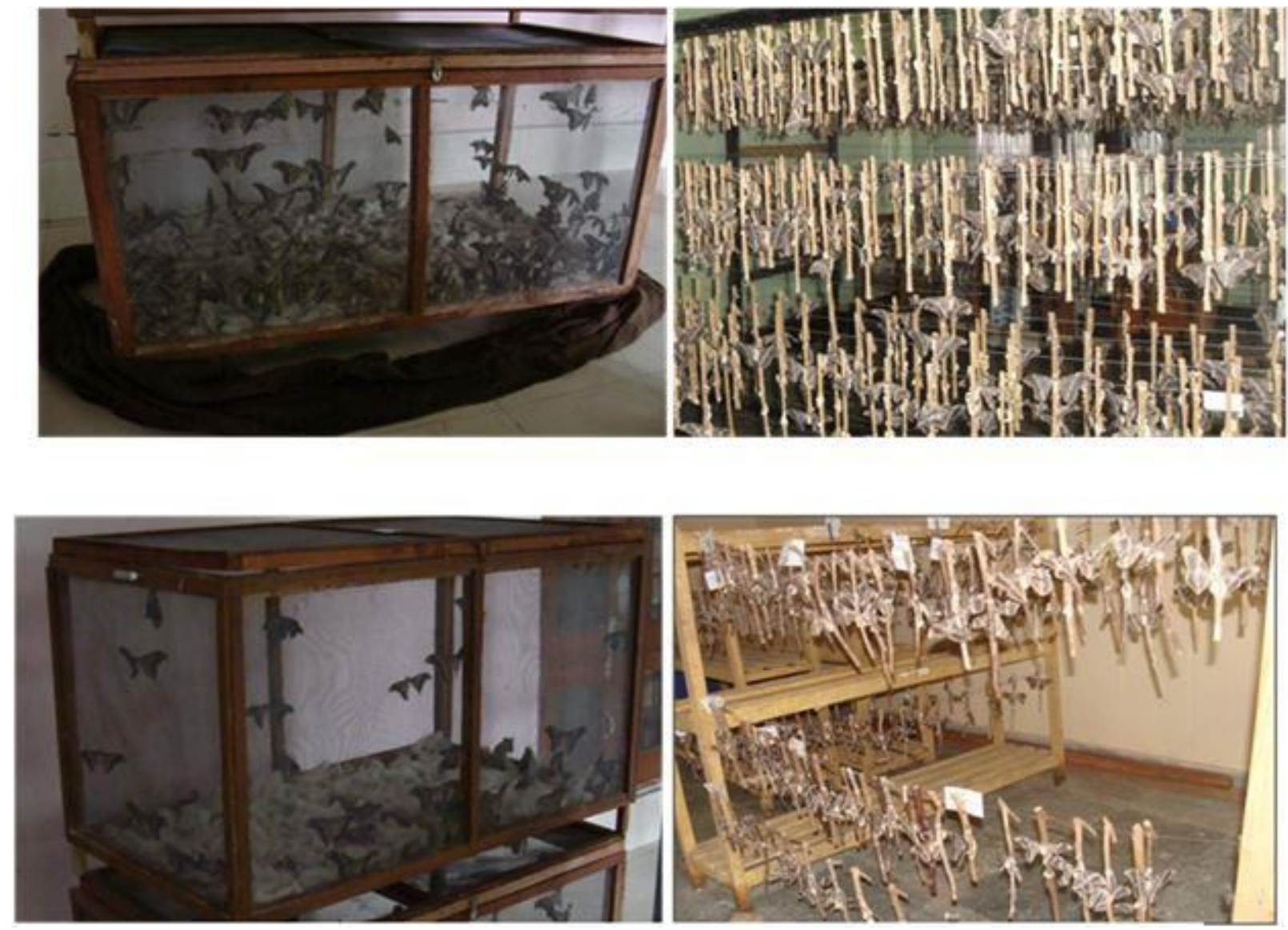

Figure 1. Treated and control lot of eri grainage.

\section{Coupling}

Coupling behaviour was different in treated and control lot of summer grainage of eri silk moths. Coupling percentage was highest $41 \%$ in treated lot and lowest $32 \%$ in control lot (Table 3 ). The healthy moths of both treated and control lot were naturally paired after one hour of emergence.

\section{Fecundity}

The effective fecundity (eggs laid) and potential fecundity (total eggs of laid and retained in ovary) were found to be highest in treated lot than control lot. In the treated lot average fecundity was recorded 310 nos. and control lot
295 nos. The average nos. of eggs retained in the ovary in treated lot is 26 and 40 in control lot.

\section{Egg characters}

The total number of eggs in one gram of eri seed in treated lot showed 570 nos. comparatively higher than control lot 574 nos. The result indicated that healthy eggs were laid in treated lot.

\section{Fertile eggs (\%)}

The percentage of fertile eggs varies with treatment and normal lot. It was found highest $88 \%$ in treated lot, 

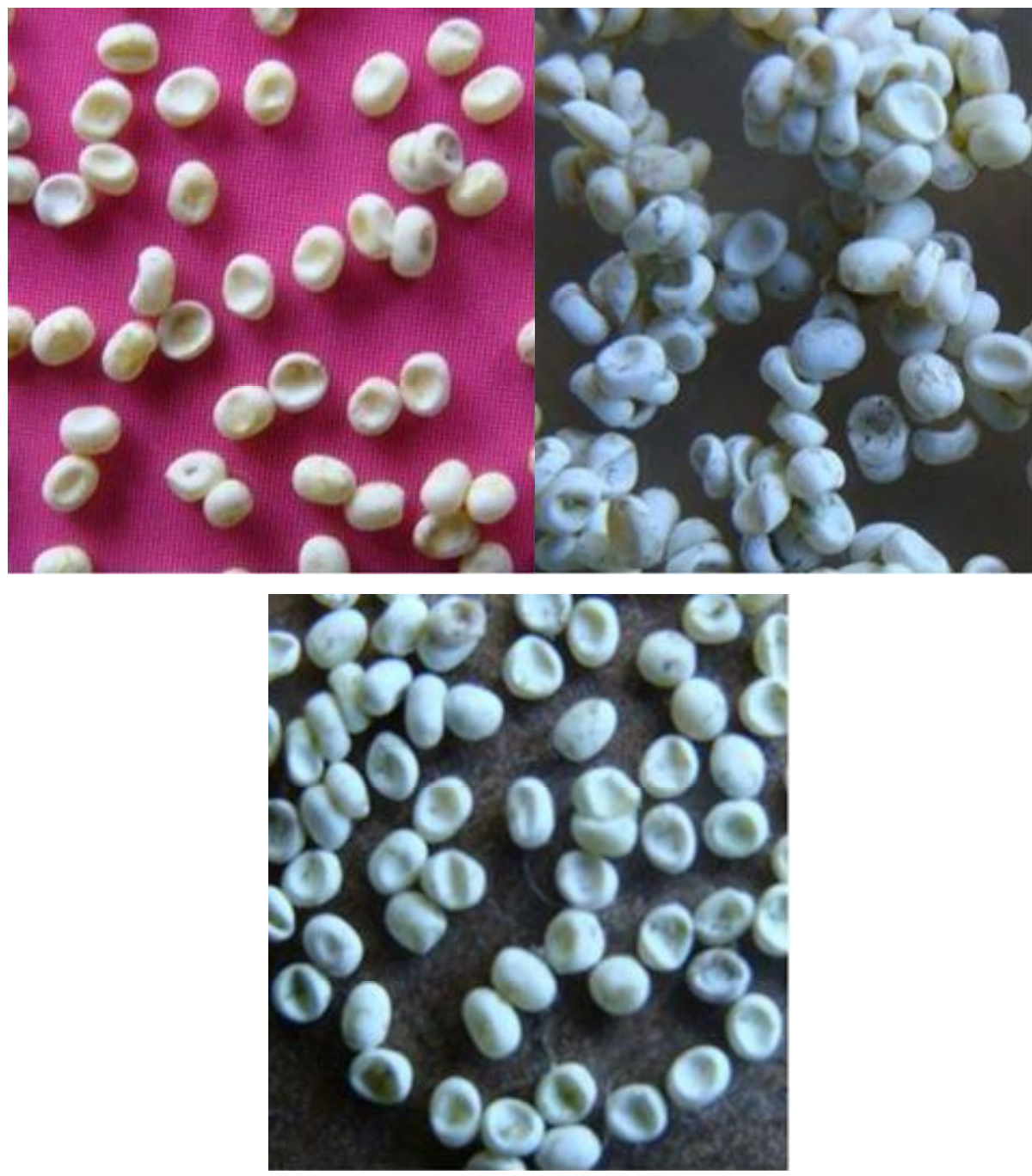

Figure 2. Desiccation of eri eggs during summer.

Table 2. Moth emergence pattern of eri silkmoth in treated and control environment.

\begin{tabular}{lccccc}
\hline Parameter & $\begin{array}{c}\text { Healthy male } \\
\text { moth }(\%)\end{array}$ & $\begin{array}{c}\text { Healthy female } \\
\text { moth }(\%)\end{array}$ & $\begin{array}{c}\text { Invalid male moth } \\
(\%)\end{array}$ & $\begin{array}{c}\text { Invalid female moth } \\
(\%)\end{array}$ & $\begin{array}{c}\text { Un emerged } \\
\text { cocoon }(\%)\end{array}$ \\
\hline Treated & 46 & 42 & 2 & 4 & 6 \\
Control & 38 & 37 & 7 & 10 & 8 \\
\hline
\end{tabular}

Table 3. Ovipositional behaviour and egg characters of eri silkworm grainage conducted in treated and normal environment.

\begin{tabular}{lccccccccc}
\hline Parameter & $\begin{array}{c}\text { Coupling } \\
\text { (\%) }\end{array}$ & $\begin{array}{c}\text { Realized } \\
\text { fecundity } \\
\text { (no.) }\end{array}$ & $\begin{array}{c}\text { Potential } \\
\text { fecundity } \\
\text { (no.) }\end{array}$ & $\begin{array}{c}\text { Eggs } \\
\text { retained } \\
\text { in ovary }\end{array}$ & $\begin{array}{c}\text { Nos. } \\
\text { eggs } \\
\text { /g (no.) }\end{array}$ & $\begin{array}{c}\text { Fertile } \\
\text { eggs } \\
\text { (\%) }\end{array}$ & $\begin{array}{c}\text { Un-fertile } \\
\text { eggs (\%) }\end{array}$ & $\begin{array}{c}\text { Hatching } \\
\text { (nos.) }\end{array}$ & $\begin{array}{c}\text { Desiccated and } \\
\text { un-hatched } \\
\text { eggs (\%) }\end{array}$ \\
\hline Treated & 41 & 310 & 336 & 26 & 570 & 88 & 12 & 69 & 19 \\
Control & 32 & 295 & 335 & 40 & 574 & 62 & 38 & 54 & 8 \\
\hline
\end{tabular}

followed by $62 \%$ in control lot. It indicates that the in treated condition the eri grainage can be conducted 
successfully.

\section{Hatching (\%)}

During the summer season with the temperature of more than 35 to $36^{\circ} \mathrm{C}$ and relative humidity less than $60 \%$ or fluctuation of temperature and humidity interfere the normal grainage activities. It was observed that maximum hatching percentage is in treated lot $69 \%$ and the lowest percentage $62 \%$ was recorded in control lot. The data reveal that in treated conditions in summer increase the hatching percentage up to $7 \%$.

\section{Desiccated eggs (\%)}

It was observed that in treated lot desiccated eggs are more than control lot. The fluctuation of temperature and humidity leads to desiccation of eri silkworm eggs and embryonic development failed in treated lot also. But, it was found the overall fecundity and hatching was better in treated lot.

\section{CONCLUSION}

The present study indicates that taking some measures, that is, using of wet gunny cloths around the lower portion of the moth emergence cage, filling up the concrete floor with running water for controlling the temperature and humidity and using of exhausted / ceiling fan to maintain cross ventilation the grainage room during the period of grainage operation showed the positive performances of eri seed production.

\section{REFERENCES}

Choudhury SN, 2005. Biology of silkworms and host plants. Published by Choudhury S.N. pp.133-134.

Engelmann F, 1984. Reproduction in insects. In Ecological Entomology.

Gogoi SN, Handique PK, Chakravorty R, 2006. Genetic conservation and improvement in castor (Ricinus communis Lin.) in North East India. In Lead papers and Abstracts, National Workshop on "Eri Food Plants", held on 11-12 October, 2006 organized by CMER\&TI, Lahdoigarh. pp. 26-29.

HazarikaU, Sarkar BN, Das K, Rajan RK, 2010. Reproductive behaviour of Samia ricini(Donovan) in relation to different food plants" $6^{\text {th }}$ International Conference on Wild Silk moths. held at Tokyo,Japan.

Samson MV, Barah A, 1989. Suggestion for better muga seed production. Indian Silk, 15: 13-18.

Sarkar BN, Sarmah MC, Chakravorty R, 2010. Seasonal variation of grainage characters in seed production of eri silkworm, Samia ricini (Donovan), Indian J Seri, 49(1): 88 - 91.

Sarkar BN, Sarmah MC, Giridhar K, 2015. Grainage performance of eri silkworm Samia ricini (Donovan) fed on different accession of castor food plants. Int j Ecol Ecosolution, 2(2): 17-21.

Sarkar DC, 1980. Ericulture in India. Central Silk board, Bombay, pp.151.
Sarmah MC, Datta RN, Das PK, Benchamin KV, 2002. Evaluation of certain castor genotypes for improving ericulture. Ind J Seri, 41(1): 62-63.

Singh BK, Debaraj Y, Sarmah MC, Das PK, Suryanarayana N, 2003. Eco-races of eri silkworm. Indian Silk, 42(1): 7-10.

Sinha AK, Choudhury SK, Brahmachari BN, Sengupta K, 1986. Foliar constituents of the food plants of temperate tasar silkworm Antheraea proylei. Ind J Seric, 25(1): 42-43.

Slansky F, Scriber JM, 1984. Food consumption and utilization. In comprehensive Insect Physiology, Biochemistry and Pharmacology (Eds. G. A. Kerkut and L. I. Gilbert). pp. 87-163.
Citation: Sarkar BN, Sarmah MC, Goswami D, 2018. Management of summer grainage of eri silkworm Samia ricini (Donovan) for better performance. Int J Ecol Ecosolution, 5(2): 13-17. 